\title{
Dependence of colour difference formulae on regular changes of colour coordinates in CIELAB colour space
}

DOI: $10.35530 / I T .070 .03 .1525$

\section{REZUMAT - ABSTRACT}

Dependența formulelor de diferență a culorii asupra modificărilor coordonatelor de culoare în spațiul de culoare CIELAB

În spațiul de culoare CIELAB au fost evaluate patru formule de diferențe de culoare [CIELAB (1976), CMC (2: 1), CIE94 (2: 1: 1) și CIEDE2000 (2: 1: 1)] pentru modificările coordonatelor de culoare. Coordonatele $L^{*}$, a* și $b^{*}$ au fost modificate atât ca etape de creștere, cât și de descreștere în diferite regiuni de luminozitate și nuanță ale spațiului de culoare. Dependența și consistența celor patru formule au fost cercetate în funcție de modificări și constante ale coordonatelor de culoare. Scopul studiului empiric a fost de a determina dacă ar putea exista o posibilitate de a utiliza diferite formule de diferențe de culoare în diferite zone de nuanță ale spațiului de culoare CIELAB; în regiunea în vrac, fiecare formulă ar da cele mai bune rezultate și cele mai fiabile rezultate. Studiul empiric a fost realizat folosind un software special care a fost pregătit pentru acest scop. Rezultatele au arătat că CIELAB și CIE94 au dat rezultate corespunzătoare între ele în intervalele de calcul. Toate formulele au prezentat diferite caracteristici de calcul în intervalele de calcul. Formula CMC a dat cele mai mari diferențe de culoare atunci când a fost calculată lângă punctul gri. S-a concluzionat că formula CIEDE2000 se potrivește cel mai bine cu modificările din etapele de calcul. Un software mai complex ar fi necesar pentru a determina sensibilitatea formulelor prin care se poate efectua calculul prin modificarea tuturor coordonatelor $\left(L^{*}\right.$, a* și $\left.b^{*}\right)$ în același timp.

Cuvinte-cheie: CIE, formula de diferență de culoare; CIELAB; CMC; CIEDE2000; CIE94

Dependence of colour difference formulae on regular changes of colour coordinates in CIELAB colour space

Four colour difference formulae [CIELAB (1976), CMC (2:1), CIE94 (2:1:1) and CIEDE2000 (2:1:1)] were assessed in CIELAB colour space for regular changes in colour coordinates. $L^{*}, a^{*}$ and $b^{*}$ coordinates were changed regularly both as increasing and decreasing steps in different lightness and hue regions of the colour space. The dependence and consistency of the four formulae were researched depending on regular and constant colour coordinate changes. The aim of the empirical study was to determine if there could be a possibility of using different colour difference formulae in different hue regions of CIELAB colour space; in the region of bulk that each formula would give the best fitting and the most reliable results. The empirical study was carried out by using a special software which was prepared for the purpose. The results showed that CIELAB and CIE94 gave corresponding results with each other in the computing ranges. All the formulae showed different computing characteristics in the computation ranges. CMC formula gave the highest colour differences when computing near the grey point. It was concluded that CIEDE2000 formula suited itself the best according to the changes in computing steps. A more complicated software would be necessary to determine the sensitivity of the formulae by which the computing would be performed by changing all the coordinates $\left(L^{*}, a^{*}\right.$ and $\left.b^{*}\right)$ at the same time.

Keywords: CIE, colour difference formula; CIELAB; CMC; CIEDE2000; CIE94

\section{INTRODUCTION}

CIE, International Commission on Illumination, defined the CIELAB colour space in 1976 which was indented to be a visually uniform one. The space was characterized by three axes that represented the three colour coordinates which were lightness $\left(L^{*}\right)$, red-green $\left(a^{*}\right)$ and yellow-blue $\left(b^{*}\right)$ together with two supplementary colour related terms of chroma $\left(C^{*}\right)$ and hue angle $\left(h^{\circ}\right)$. After the calculation of the three tristimulus values ( $\mathrm{X}, \mathrm{Y}$, and $\mathrm{Z}$ ) under specified illumination and viewing conditions, they are used as the computing components in the calculation of colour coordinates to designate the place of the colour in CIELAB colour space. Together with the definition of CIELAB colour space, CIELAB (1976) colour difference formula was developed to calculate the colour difference between two colours in the space.
However, CIELAB colour space is not truly visually uniform which means that equal colour difference magnitude appear of different visual magnitudes in different regions of the colour space.

When the difference between two colours are calculated by CIELAB colour difference formula, the formula calculates the linear (Euclidean) distance between the two points in the CIELAB colour space by using the three colour coordinates of $L^{*}, a^{*}$ and $b^{*}$. Because of the non-uniformity of the CIELAB colour space and the setup of CIELAB (1976) formula, the colour difference obtained is free from human eye sensitivity. Human eye is sensitive to different kinds of changes in the shade(s) under observation. Human visual system perceives the differences in different magnitudes even though they may have the same colour difference calculated by CIELAB (1976) 
formula. For this reason, the same vector distance may not be perceptually the same for all colours.

A perceptually uniform colour space is the one in which Euclidean distances highly agree with perceptual colour differences. Originating from the problem of inconsistency of calculated and visual colour differences, advanced colour difference formulae were developed which were based on the modification of CIELAB [1]. New colour spaces like CIELAB and colour appearance spaces like CIECAM02 were researched in recent years [2-3]. But perceptual uniformity of these spaces were found insufficient for various applications so that new colour difference formulae were developed and standardized, such as CMC [4], CIE94 [5] and CIEDE2000 [6, 7]. Visual experiments showed that the CIECAM02 space was also not perceptually uniform and new colour difference formulae could be applied to enhance the correlation to the visual data. The scientific approach related with this subject was well established by Urban et al. Papers were published to discuss the new formula CIEDE2000 [8-13].

Human visual system is sensitive to naturals and high-chroma colours depending on their lightness and chroma values. But the sensitivity is ruled in different characteristics in different parts of the CIELAB colour space and on $a^{*}-b^{*}$ colour plane. For this reason, determination of the exact combination and point of hue angle and its related chroma of a colour on $a^{*}-b^{*}$ colour plane is important in the calculation of colour difference. The advanced colour difference formulae differ from each other in the way of more precise calculation of chroma and hue differences in CIELAB colour space.

Colour is very important for human life because human beings have their own individual colour choices in every phase of daily life. In textiles, uniform colour is important especially in plain garments because these garments are made of many different parts which were cut in preparation and later associated to each other by means of sewing. But each part cannot be chosen from the same area but collected from different parts of the whole fabric depending on the applications which are carried out by ready cloth making industry. For this reason there is a need for a precise colour difference formula for colour matching. Questions arise which formula should be used according to different magnitudes in industrial applications or it would be possible to use a hybrid system to deal with different colour difference changes [14].

Evaluation of colour difference formulae for different colour-difference magnitudes were carried out by researchers. Wang et al. found that colour-difference formulae performed significantly different when applied to estimate large and small colour differences. They extended the CIE recommended colour space model, CIECAM02, to form three new uniform colour spaces, CAM02-SDC, CAM02-LCD and CAM02-UCS, for estimating small-, large-, and overall ranges of colour differences respectively [14]. Xu et al. tested CIELAB-based colour-difference formulae using large colour differences [10].
Melgosa published testing results of CIELAB-based colour difference formulae [15]. Kandi and Tehran investigated the effect of fabric texture on the performance of colour difference formula [16]. Becerir discussed the differences between CIEL* $a * b *$ and Hunter L, a, b colour coordinates by wash fastness tests [17]. Sennaroglu et al. used CMC formula in accordance with artificial neural network.

This paper researched the responses of four colour difference formulae in different lightness and hue regions of CIELAB colour space and tried to investigate the consistency of the formulae from small to very large colour differences.

\section{MATERIALS AND METHODS}

Dependence of colour difference formulae on regular changes of colour coordinates in CIELAB colour space was researched by a specially prepared software. The software was prepared by using C\# programming. Colour difference formulae were prepared as Excel worksheet and they were used as the computation references in the software. The software prepared the results again in Excel worksheet between the preferred limits of coordinates. In order to make a better graphical presentation, four or five results were omitted in the related figures otherwise a black line was obtained for each formula which enabled to make differentiation between lines and curves. The

Table 1

START AND END POINTS OF LIGHTNESS COORDINATE FOR INCREASING AND DECREASING COMPUTING

\begin{tabular}{|l|c|c|c|c|c|c|}
\hline \multirow{2}{*}{ Figure } & \multicolumn{3}{|c|}{ Start point } & \multicolumn{3}{c|}{ End point } \\
\cline { 2 - 8 } & $\mathbf{L}^{*}$ & $\mathbf{a}^{*}$ & $\mathbf{b}^{*}$ & $\mathbf{L}^{*}$ & $\mathbf{a}^{*}$ & $\mathbf{b}^{*}$ \\
\hline Figure 1, $a$ & 20 & 1 & 1 & 95 & 1 & 1 \\
\hline Figure 1, $b$ & 95 & 1 & 1 & 20 & 1 & 1 \\
\hline Figure 2, $a$ & 50 & 1 & 1 & 100 & 1 & 1 \\
\hline Figure 2, $b$ & 50 & 1 & 1 & 0 & 1 & 1 \\
\hline
\end{tabular}

Table 2

START AND END POINTS OF RED-GREEN AND

YELLOW-BLUE COORDINATES FOR INCREASING AND DECREASING COMPUTING

\begin{tabular}{|l|c|c|c|c|}
\hline \multirow{2}{*}{ Figure } & \multicolumn{2}{|c|}{ Start point } & \multicolumn{2}{c|}{ End point } \\
\cline { 2 - 5 } & $\mathbf{a}^{*}$ & $\mathbf{b}^{*}$ & $\mathbf{a}^{*}$ & $\mathbf{b}^{*}$ \\
\hline Figure 3, $a$ & -30 & 0 & 0 & 30 \\
\hline Figure 3, $b$ & 0 & 30 & -30 & 0 \\
\hline Figure 4, $a$ & 0 & -30 & 30 & 0 \\
\hline Figure 4, $b$ & 30 & 0 & 0 & -30 \\
\hline Figure 5, $a$ & -30 & -30 & 30 & 30 \\
\hline Figure 5, $b$ & 30 & 30 & -30 & -30 \\
\hline Figure 6, $a$ & -30 & -30 & $-0,01$ & $-0,01$ \\
\hline Figure 6, $b$ & $-0,01$ & $-0,01$ & -30 & -30 \\
\hline Figure 7, $a$ & 0,01 & 0,01 & 30 & 30 \\
\hline Figure 7,b & 30 & 30 & 0,01 & 0,01 \\
\hline
\end{tabular}


start points presented in tables 1 and 2 were taken as the "Reference" colour in computing. "Sample" colours were the ones which were obtained by regular step increases or decreases in the corresponding coordinates.

\section{RESULTS AND DISCUSSION}

Dependence of four colour difference formulae on regular changes in lightness $\left(L^{*}\right)$ coordinate was assessed in figures 1 and 2 for different start and end points. Lightness coordinates were changed between 0 and 100 at the point of $a^{*}=b^{*}=1$. Coordinates were increased and decreased by 0.25 units at regular steps in the corresponding figures. Start and end points of the lightness coordinate were presented in table 1 for the corresponding figures.

Colour difference results were calculated between $L^{*}=20$ and $L^{*}=95$ by 0.25 units of increases and decreases in figures $1, a$ and $1, b$ respectively. $L^{*}=20$ coordinate was chosen as the minimum lightness coordinate because of the computing rule of $\mathrm{CMC}$ formula at $L^{*}=16$. Colour difference results were computed between $L^{*}=50$ and $L^{*}=100$ by 0.25 units of increase in figure 2, a and they were computed between $L^{*}=50$ and $L^{*}=0$ by 0.25 units of decrease in figure $2, b$.

An overall discussion of the computed colour differences which were presented in figures 1 and 2 showed that colour difference results obtained by computing according to CIELAB, CMC and CIE94 formulae resulted in linear matching (a line) while computing according to CIEDE2000 formula resulted in a curve matching (ascending or descending).
Computing according to CIE94 formula gave almost the half results of computing according to CIELAB formula in figures 1 and 2 . Computing according to these two formulae were insensitive to regular increases or decreases at the lightness coordinate. They always retained their corresponding own values although the computing ranges changed in opposite directions in figures $1, a-1, b$ and figures $2, a-2, b$. In figures $1, a$ and $1, b$, the colour difference computing was performed in opposite directions (increasing or decreasing steps) between $L^{*}=20$ and $L^{*}=95$. Both CMC and CIEDE2000 formulae gave two distinctly different results of their own although only the start and end points had changed on lightness axis. CMC results were very high in figure 1 , a but they were the lowest in figure $1, b$. Computing according to CIEDE2000 formula gave two different polynomial curves.

In figures 2, $a$ and 2, b, CIEDE2000 formula gave the same results in the computing ranges. CMC formula would also give the same results in the computing ranges in figures 2, $a$ and $2, b$ as understood from its' lines in the figures but because of its' formula specialty at $L^{*}=16$, a step increase was obtained in figure $2, b$ at the computing point of $L^{*}=16$.

CIELAB and CIE94 results were consistent with lightness changes in the different computing ranges presented in figures $1, a-1, b$ and figures $2, a-2, b$. CMC and CIEDE2000 results were even when computing was performed from $L^{*}=50$ to $L^{*}=100$ (figure 2 , a) and from $L^{*}=50$ to $L^{*}=0$ (fig. $2, b$ ). But the characteristic of their results changed considerably when computing was performed between $L^{*}=20$ and $L^{*}=95$ (figures $1, a-1, b)$ both in increasing and decreasing steps.

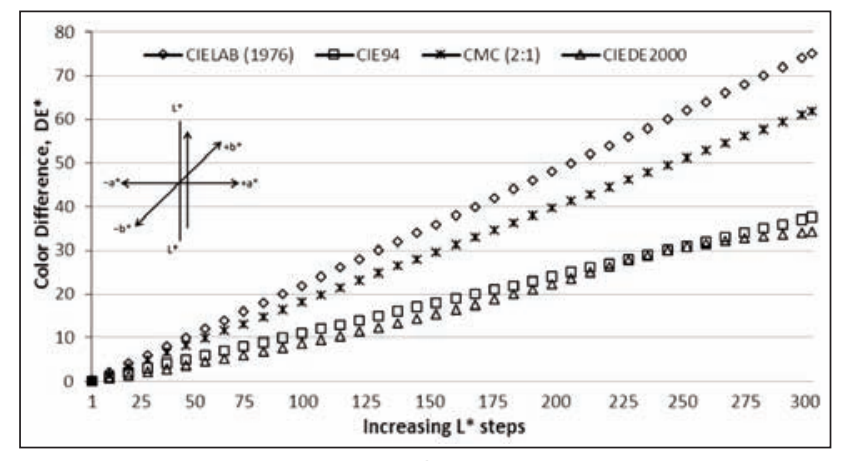

a

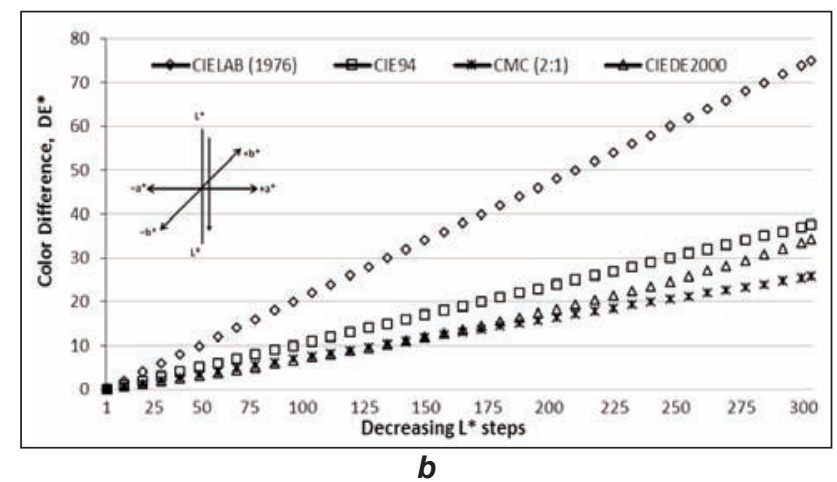

Fig. 1. Colour difference results (from $L^{*}=20$ to $L^{*}=95$; $\left.a^{*}=b^{*}=1\right)(a)$; Colour difference results (from $L^{*}=95$ to $\left.L^{*}=20 ; a^{*}=b^{*}=1\right)(b)$

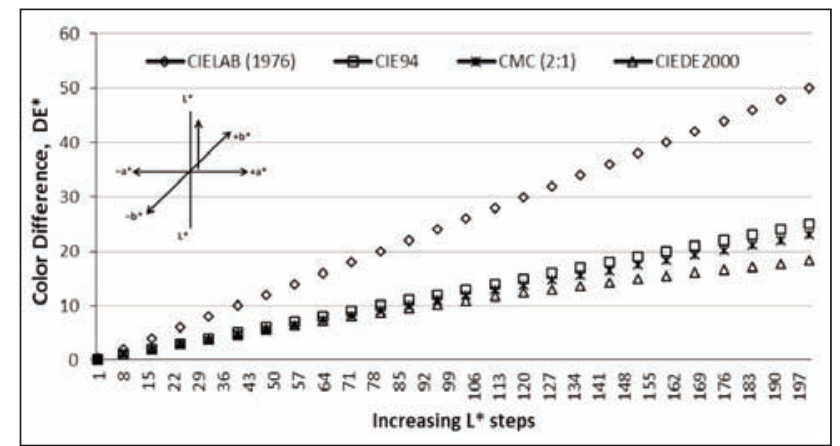

a

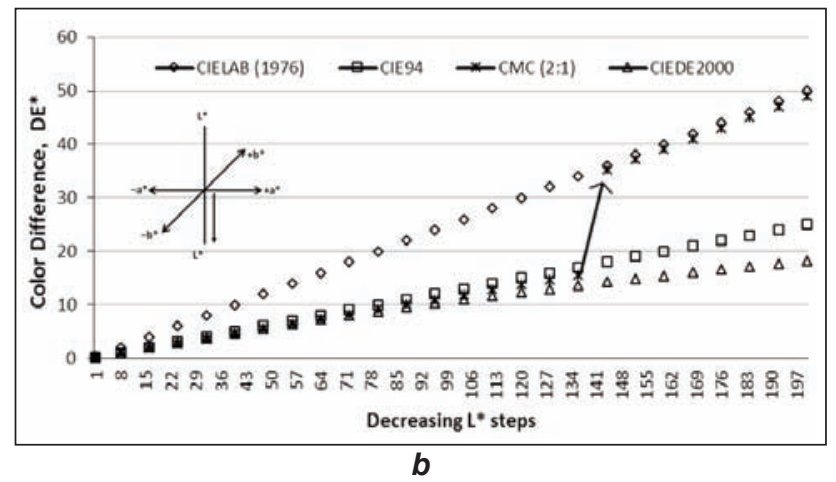

Fig. 2. Colour difference results (from $L^{*}=50$ to $L^{*}=100$; $\left.a^{*}=b^{*}=1\right)(a)$; Colour difference results (from $L^{*}=100$ to $\left.L^{*}=50 ; a^{*}=b^{*}=1\right)(b)$ 
Dependence of the four colour difference formulae on regular changes of red-green $\left(a^{*}\right)$ and yellow-blue $\left(b^{*}\right)$ coordinates were assessed in figures $3-7$ for different hue regions and start and end points. Lightness $\left(L^{*}\right)$ coordinate was taken as $L^{*}=50$ constant in all computations so that all the calculations were conducted on $a^{*}-b^{*}$ colour plane at $L^{*}=50$. $a^{*}$ and $b^{*}$ coordinates were increased or decreased by 0.30 units between start and end points in the four sub-regions (hue regions) of $a^{*}-b^{*}$ colour plane. The computing results were presented in the corresponding figures.

The computing was conducted in the second hue region $\left(90^{\circ}-180^{\circ}\right)$ of $a^{*}-b^{*}$ colour plane at increasing and decreasing steps in figures $3, a$ and $3, b$ respectively. Linear results were obtained by CIELAB formula while polynomial results were obtained by the other three formulae. CIELAB and CIE94 formulae gave the same results of their own in figures 3 , $a$ and $3, b$. CMC and CIEDE2000 gave two different polynomial curves of their own although only the computing direction had changed. The highest colour difference results were obtained by CIELAB when computing was performed in increasing steps in figure 3 , a while the highest colour difference results were obtained by CMC when computing was performed in decreasing steps in figure $3, b$.

The computing was conducted in the fourth hue region $\left(270^{\circ}-360^{\circ}\right)$ of $a^{*}-b^{*}$ colour plane at increasing and decreasing steps in figures $4, a$ and $4, b$ respectively. Similar to the results presented in figures $3, a$ and $3, b$, linear results were obtained by CIELAB and polynomial results were obtained by the other three formulae. Also the same colour difference
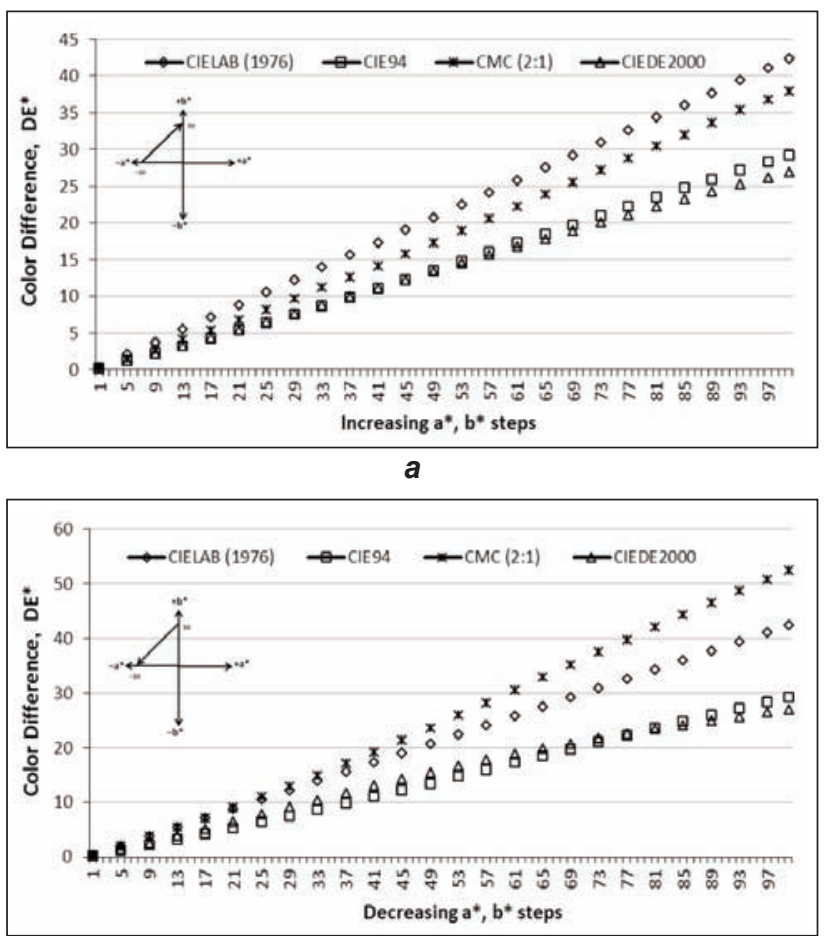

b

Fig. 3. Colour difference results (from $a^{*}=-30, b^{*}=0$ to $\left.a^{*}=0, b^{*}=30 ; L^{*}=50\right)(a)$; Colour difference results (from $a^{*}=0, b^{*}=30$ to $a^{*}=-30, b^{*}=0 ; L^{*}=50$ ) (b) results were obtained by CIELAB in figures 3-4. CIE94 gave the same results in figures $4, a$ and $4, b$ but different from its behaviour in figures $3, a$ and $3, b$, the computed results were not almost the half of CIELAB results. CMC and CIEDE2000 gave two different polynomial curves of their own although only the computing direction had changed, similar to the results presented in figures $3, a$ and $3, b$. The highest colour difference results were obtained by CIELAB when computing was performed both in increasing and decreasing steps in figures $4, a$ and $4, b$. The lowest colour difference results were obtained by CMC when computing was performed in increasing steps in figure $4, a$. CMC colour difference results presented a different character when the computing was performed in decreasing steps in figure $4, b$ and they were very close to the results of CIELAB.

The computing was conducted starting from the third hue region $\left(180^{\circ}-270^{\circ}\right)\left(a^{*}=b^{*}=-30\right)$ to ending in the first hue region $\left(0^{\circ}-90^{\circ}\right)\left(a^{*}=b^{*}=30\right)$ and starting from the first hue region $\left(a^{*}=b^{*}=30\right)$ to ending in the third hue region $\left(a^{*}=b^{*}=-30\right)$ of $a^{*}-b^{*}$ colour plane in figures $5, a$ and $5, b$ respectively. Similar to the results presented in figures $3-4$, linear results were obtained by CIELAB and polynomial results were obtained by the other three formulae. CIELAB, CIE94 and CIEDE2000 gave individually the same results of their own in figures $5, a$ and 5, $b$. CMC, CIE94 and CIEDE2000 gave thresholds at the grey point of $\left(a^{*}=b^{*}=0 ; L^{*}=50\right)$ $a^{*}-b^{*}$ colour plane. The three formulae changed their computing character while passing the grey point. The highest colour difference values were obtained by CIELAB when computing both in increasing and decreasing steps in figures $5, a$ and $5, b$. CMC results

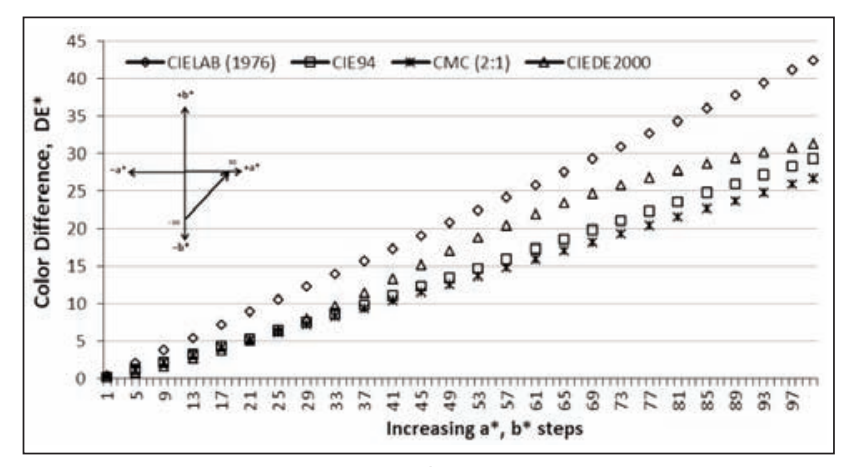

a

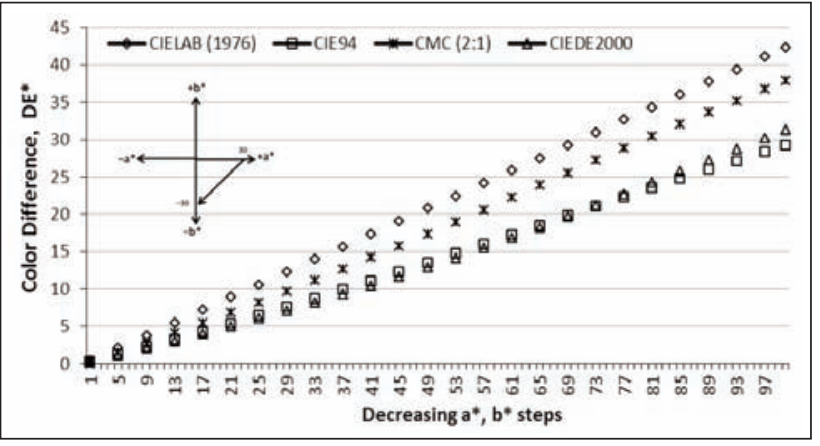

b

Fig. 4. Colour difference results (from $a^{*}=0, b^{*}=-30$ to $\left.a^{*}=30, b^{*}=0 ; L^{*}=50\right)(a)$; Colour difference results (from $a^{*}=30, b^{*}=0$ to $a^{*}=0, b^{*}=-30 ; L^{*}=50$ ) (b) 


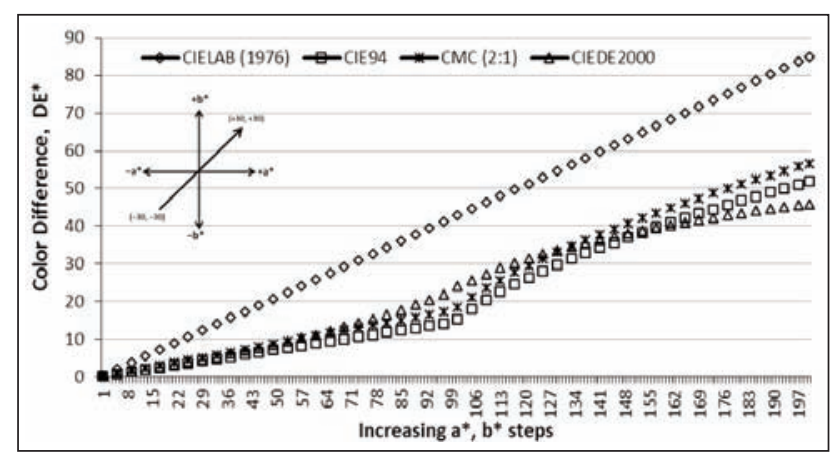

a

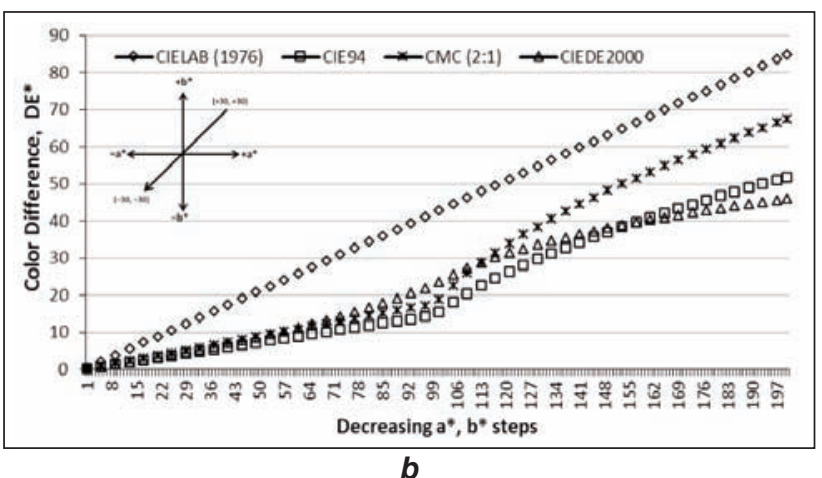

Fig. 5. Colour difference results (from $a^{*}=-30, b^{*}=-30$ to $\left.a^{*}=30, b^{*}=30 ; L^{*}=50\right)(a)$; Colour difference results (from $a^{*}=30, b^{*}=30$ to $a^{*}=-30, b^{*}=-30 ; L^{*}=50$ ) (b)

differed considerably when computing direction had changed, similar to figures $3-4$.

The computing was conducted in the third hue region $\left(180^{\circ}-270^{\circ}\right)$ of $a^{*}-b^{*}$ colour plane at increasing and decreasing steps in figures $6, a$ and $6, b$ respectively. Polynomial results were obtained by CIEDE2000 and linear results were obtained by the other three formulae. CIELAB gave the same results in figures $6, a$ and $6, b$. Also almost the same results were obtained when computing was performed according to CIELAB and CIE94 in figure 6,b. Computing according to CMC and CIEDE2000 showed distinct differences when computing direction had changed in figures $6, a$ and $6, b$. CIEDE2000 gave ascending and descending curves in figures $6, a$ and $6, b$ respectively. CMC results were the lowest ones with CIE94 results in figure 6 , a but $\mathrm{CMC}$ results were far the highest one in figure $6, b$. Computing according to CMC, CIE94 and CIEDE2000 gave distinct differences in the third hue region of $a^{*}-b^{*}$ colour plane when computing directions were changed.

The computing was conducted in the first hue region $\left(0^{\circ}-90^{\circ}\right)$ of $a^{*}-b^{*}$ colour plane at increasing and decreasing steps in figures $7, a$ and $7, b$ respectively. Similar to the results presented in figures $6, a$ and $6, b$, polynomial results were obtained by CIEDE2000 and linear results were obtained by the other three formulae. CIELAB gave the same results in figures 6-7 irrespective of the hue region and computing direction. Also similar to figure $6, b$, CIELAB and CIE94 gave almost the same results in figure $7, a$, and computing according to CMC and CIEDE2000 showed distinct differences when computing direction had changed in figures $7, a$ and $7, b$. CIEDE2000

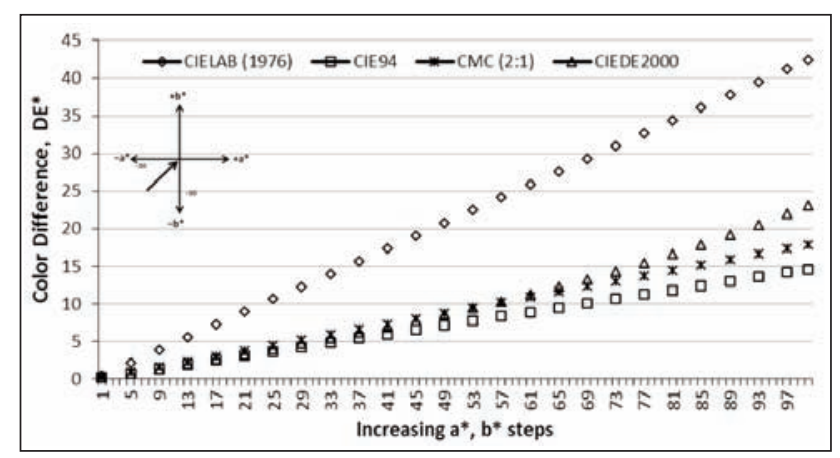

a

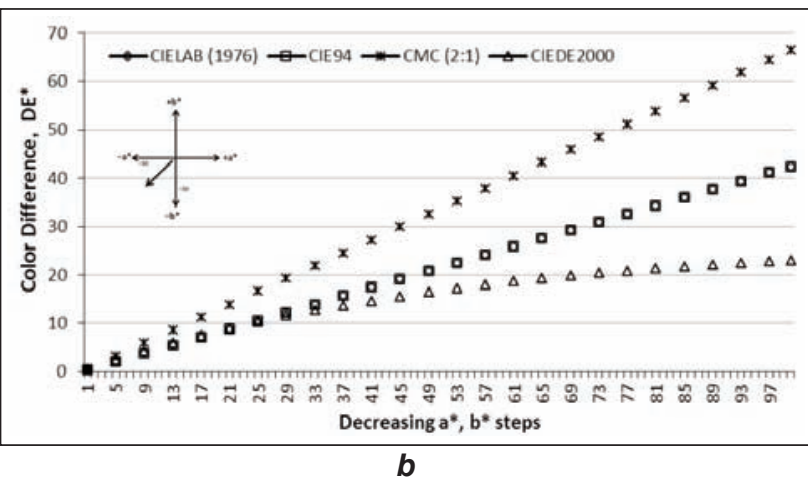

Fig. 6. Colour difference results (from $a^{*}=-30, b^{*}=-30$ to $\left.a^{*}=-0.01, b^{*}=-0.01 ; L^{*}=50\right)(a)$; Colour difference results (from $a^{*}=-0.01, b^{*}=-0.01$ to $\left.a^{*}=-30, b^{*}=-30 ; L^{*}=50\right)(b)$

gave descending and ascending curves in figures $7, a$ and $7, b$ respectively. The highest colour differences were obtained when computing was performed according to $\mathrm{CMC}$ in figure $7, a$.

When figures 6-7 were considered closer, it was observed that figures $6, a$ and $7, b$, and figures $6, b$ and $7, a$ were the same; i.e., the same colour difference results were obtained. This meant that computing in the third hue region with increasing steps (figure 6,a) and computing in the first region with decreasing steps (figure $7, b$ ) resulted in the same colour difference values, i.e., when the computing was performed approaching to the grey point $\left(a^{*}=b^{*}=0 ; L^{*}=50\right)$. Similarly, computing in the third hue region with decreasing steps (figure $6, b$ ) and computing in the first region with increasing steps (figure $7, a$ ) resulted in the same colour difference values, i.e., when computing was performed receding from the grey point $\left(a^{*}=b^{*}=0 ; L^{*}=50\right)$.

An overall consideration of figures $1-2$, where $L^{*}$ coordinates were increased and decreased at constant steps at the point of $a^{*}=b^{*}=1$, showed that CIELAB gave linear and the same results in the corresponding figures $1, a-1, b$ and $2, a-2, b$. Also CIE94 gave almost the half results of CIELAB in figures 1-2. CMC and CIEDE2000 gave characteristic results when computing was performed at increasing and decreasing steps between $L^{*}=20$ and $L^{*}=95$ in figures $1, a$ and $1, b$. These two formulae gave the same results of their own when computing was performed above and under $L^{*}=50$ (figures $2, a$ and $2, b$ ). The only exception was CMC formula in figure $2, b$ because of its specialty at $L^{*}=16$. 


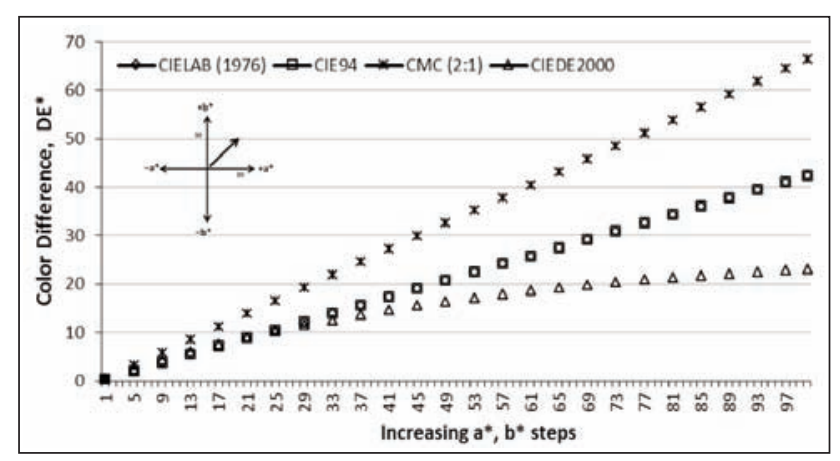

a

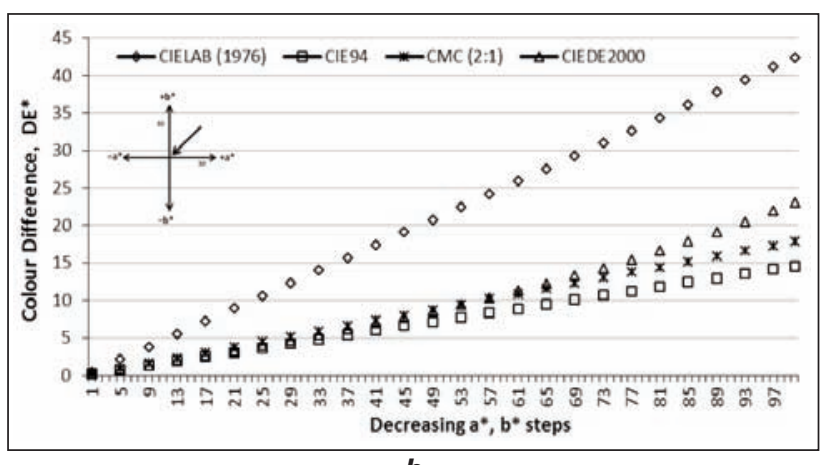

b

Fig. 7. Colour difference results (from $a^{*}=0.01, b^{*}=0.01$ to $\left.a^{*}=30, b^{*}=30 ; L^{*}=50\right)(a)$; Colour difference results (from $a^{*}=30, b^{*}=30$ to $\left.a^{*}=0.01, b^{*}=0.01 ; L^{*}=50\right)(b)$

An overall consideration of figures $3-4$, where $a^{*}$ and $\mathrm{b}^{*}$ coordinates were increased and decreased at constant steps on the second and on the fourth hue regions of $a^{*}-b^{*}$ colour plane, showed that the same linear equation was obtained for CIELAB in all computing indicating that CIELAB formula was consistent to computing in any hue area of the CIELAB colour space either the computing was performed at constant increasing or decreasing steps. This fact had been already known in colour science because of the regular computing (calculation) characteristic of the CIELAB formula. Similar to CIELAB results, CIE94 formula gave the same results of its own in the corresponding figures $3-4$. CIE94 formula gave results which indicated that it was insensitive to computing in regular increasing and decreasing steps in the second and the fourth hue regions of $a^{*}-b^{*}$ colour plane. On the other hand, CMC formula was sensitive to the second and the fourth hue regions and to regular increasing and decreasing steps in the corresponding figures of 3-4. However, CMC formula gave almost the same results when computing was performed in the second hue region of $a^{*}-b^{*}$ colour plane according to increasing steps (figure $3, a$ ) and in the fourth region of $a^{*}-b^{*}$ colour plane according to decreasing steps (figure $4, a)$. A corresponding behaviour was not observed in the same regions when computing direction changed, in figures $3, b$ and $4, a$. CIEDE2000 formula was sensitive to regularly increasing and decreasing steps in the second and fourth hue regions of $a^{*}-b^{*}$ colour plane. Regular descending curves were obtained in the second hue region of $a^{*}-b^{*}$ colour plane (figures $3, a$ and $3, b$ ). However, a completely different character was obtained in figures $4, a$ and
$4, b$ where the computing was performed in the fourth hue region. The polynomial curves obtained in this region for regularly increasing and decreasing steps differed from each other considerably.

An overall consideration of figures $5, a-5, b$ where $a^{*}$ and $b^{*}$ coordinates were increased and decreased at constant steps through the first and third regions of $a^{*}-b^{*}$ colour plane at $L^{*}=50$, showed that only CMC formula gave different results in the corresponding figures while the other three formulae gave the same results of their own. CIELAB gave linear results similar to the ones presented in figures 1-4. CMC, CIE94 and CIEDE2000 gave thresholds when computing passed through the grey point of $a^{*}-b^{*}$ colour plane. CIEDE2000 results changed from ascending character to descending character while CMC and CIE94 results considerably increased in a descending character in both figures of $5, a$ and $5, b$.

An overall consideration of figures $6-7$ where $a^{*}$ and $b^{*}$ coordinates were increased and decreased at constant steps the third (figures $6, a$ and $6, b$ ) and in the first (figures $7, a$ and $7, b$ ) regions of $a^{*}-b^{*}$ colour plane at $L^{*}=50$, showed that all the four formulae were sensitive to computing according to regular changes in the third and first hue regions of $a^{*}-b^{*}$ colour plane. Computing according to increasing steps in the third hue region (figure $6, a$ ) corresponded with computing to decreasing steps in the first hue region (figure $7, b$ ) and computing according to increasing steps in the first hue region (figure $7, a$ ) corresponded with computing according to decreasing steps in the third hue region (figure $6, b$ ). The four formulae gave corresponding results of their own when computing came closer to the grey point (fig- ures $6, a$ and $7, b$ ) and when the computing receded from the grey point (figures $6, b$ and $7, a$ ). CMC formula gave the highest colour difference results when the computing receded from the grey point and also CIELAB and CIE94 gave almost the same results.

The computing characteristics of the four formulae changed considerably in the four hue regions not only depending on the colours (hues) in the region but also on the way of calculation of colour differences either in increasing or decreasing steps. Studies are being carried out by researchers on real colours and real observers to make a final conclusion about the choice of the most reliable formula but this research revealed that the continuity of the computing characteristics of the âformulae in CIELAB colour space were also important. Depending on the computing results presented in this paper, it was concluded that CIEDE2000 formula suited itself the best according to the changes in computing steps.

\section{CONCLUSION}

The purpose of this paper was to research the computing characteristics of the four colour difference formulae according to regular coordinate changes in the CIELAB colour space. The computing applications were made on lightness axis and on four hue regions of $a^{*}-b^{*}$ colour plane. Questions arise on the possibility of usage of the colour difference formulae in CIELAB colour space because of the ununiformity 
of the space. This research tried to find a possible answer if it would be suitable or convenient to use different colour difference formulae in different hue regions of CIELAB colour space. The computing revealed that $C I E L A B$ formula was insensitive to regular lightness and hue changes in the colour space and always linear character of colour difference was obtained. CIEDE2000 always gave polynomial results wherever the computing was carried out. The most differing colour difference results were obtained by CMC and CIELAB2000. Especially CMC formula showed distinct differences when computing changed from regular increases to regular decreases or vice versa in different hue regions. It could be stated that the more the results of a colour difference formula dif- fer according to computing regions of $a^{*}-b^{*}$ colour plane the more sensitive the formula to the changes in hue differences. If this statement could be considered as true, then CMC and CIEDE2000 formulae would be judged as the most sensitive colour difference formulae to regular changes in hue. However, CMC gave very distinct values especially when the computing directions changed. CIEDE2000 formula resulted in more even results than the others and implied that it could suit itself to the computing areas and directions better than the others.

\section{ACKNOWLEDGEMENT}

The authors thank M. Medeni Baykal for his kind support in the preparation of the computing software.

\section{BIBLIOGRAPHY}

[1] Urban, P., Berns, S.R., Rosen, M.R. Constructing Euclidean color spaces on color difference formulas, In: $15^{\text {th }}$ Color Imaging Conference Final Program and Proceedings, Society for Imaging Science and Technology, 2007, pp. 77-82.

[2] CIE, A colour appearance model for colour management systems: CIECAM02, CIE Publication No. 159-2004.CIE Central Bureau, Vienna, Austria, 2004

[3] Luo M.R., Cui G., Li C. Uniform colour spaces based on CIECAM02 colour appearance model, In: Color Research and Application, 2006, vol. 31, no. 4, pp. 320-330.

[4] BS 6923, Method for calculation of small color differences. Committee of the Society of Dyers and Coloristsand British Standard Institution, London, UK, 1988.

[5] CIE, Industrial colour-difference evaluation, CIE Publication No. 116-1995, CIE Central Bureau, Vienna, Austria, 1995.

[6] CIE, Improvement to industrial colour-difference evaluation. CIE Publication No. 142-2001, CIE Central Bureau, Vienna, Austria, 2001

[7] Luo, M.R., Cui, G., Rigg B. The development of the CIE 2000 colour-difference formula: CIEDE2000, In: Color Research and Application, 2001, vol. 26, no. 5, pp. 340-350.

[8] Luo, M.R., Cui, G., Rigg, B. Further comments on CIEDE2000, In: Color Research and Application, 2002, vol. 27, no. 2, pp. 127-128.

[9] Kuehni, R.G., CIEDE2000: milestone of final answer?, In: Color Research and Application, 2002, vol. 27, no. 2, pp. 126-127.

[10] Xu, H., Yaguchi, H., Shiori, S. Testing CIELAB-based color-difference formulae using large color differences, In: Optical Review, 2001, vol. 8, no. 6, pp. 487-494.

[11] Sharma, G., Wu, W., Dalal, E.N. The CIEDE2000 color-difference formula: Implementation notes, Supplementary test data, and mathematical observations, In: Color Research and Application, 2005, vol. 30, no. 1, pp. 21-30.

[12] Yang, Y., Ming, J., Yu, N. Color image quality assessment based on CIEDE2000, In: Advances in Multimedia; 2012, Article ID 273723, 6 pages, doi:10.1155/2012/273723.

[13] Luo, M.R., Rigg, B. Chromaticity-discrimination ellipses for surface colours, In: Color Research and Application, 1986, vol. 11, no. 1, pp. 25-42.

[14] Wang, H., Cui, G., Luo, R., Xu, H. Evaluation of colour-difference formulae for different colour-difference magnitudes, In: Color Research and Application, 2012, vol. 37, no. 5, pp. 316-325.

[15] Melgosa, M. Testing CIELAB-based color difference formulas, In: Color Research and Application, 2000, vol. 25, no. 1 , pp. $49-55$.

[16] Kandi, S.G., Tehran, M.A. Investigating the effect of texture on the performance of color difference formulae, In: Color Research and Application, 2010, vol. 35, no. 2, pp. 94-100.

[17] Becerir, B. Assessment of colour properties of reactive dyed cotton fabrics under different illuminants by using CIELAB and hunter systems, In: Tekstilve Konfeksiyon, 2010, vol. 20, no. 2, pp. 145-154.

[18] Sennaroglu, B., Oner, E., Senvar, O. Colour recipe prediction in dyeing acrylic fabrics with fluorescent dyes using artificial neural network, In: Indutria Textila, 2014, vol. 65, no. 1, pp. 22-28.

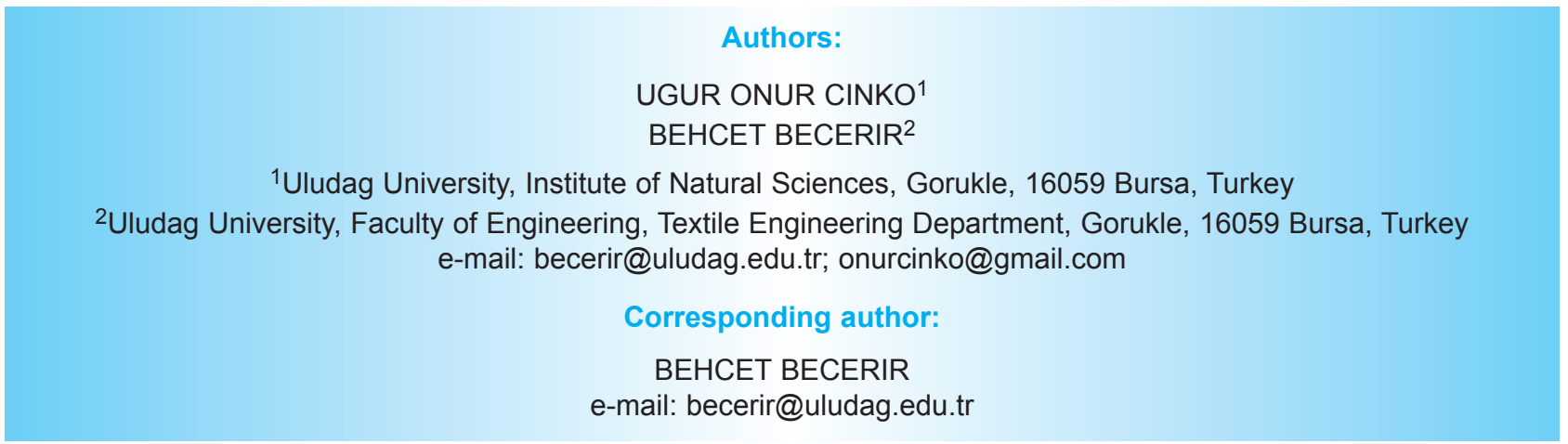

